\title{
Educação e Interpretação Ambiental na RPPN Estação Veracel, Porto Seguro (BA)
}

\author{
Environmental Education and Interpretation in RPPN Veracel \\ Station, Porto Seguro (BA, Brazil)
}

\author{
Renata Coppieters Oliveira de Carvalho, Salete Vieira
}

\begin{abstract}
RESUMO
A Reserva Particular do Patrimônio Natural Estação Veracel (RPPN EVC) está localizado no município turístico de Porto Seguro no extremo sul da Bahia. Esta unidade de conservação (UC) possui Plano de Manejo que oferece parâmetros para a visitação no programa de uso público. O programa tem como foco principal a educação ambiental através de trilhas interpretativas e cursos de capacitação local, sem objetivar lucro. Os visitantes são caracterizados por estudantes, professores da rede pública e privada, além de profissionais liberais e pesquisadores de origem nacional e internacional. Desta forma, o objetivo deste artigo é analisar a comunicação realizada na visitação à RPNN Veracel, através da observação da trilha Floresta Tropical comparando as técnicas utilizadas de Educação Ambiental e Interpretação do Patrimônio Ambiental. Para tanto se utilizou a metodologia descritiva para analisar a oferta da Reserva, pesquisa de campo com registros fotográficos e roteiro semiestruturado de observação, coletados nos anos de 2011, 2012 e 2013, confrontando com o referencial teórico sobre a Interpretação do Patrimônio e Educação Ambiental. Encontra-se nesta UC uma extensa área de preservação de Mata Atlântica com trechos de mata primária e proteção a espécie do gavião real. As ações realizadas são relevantes, mas ainda pouco explorada no que tange ao seu imenso potencial de educação.
\end{abstract}

PALAVRAS-CHAVE: Veracel; Mata Atlântica; Turismo; Visitação; Celulose.

\begin{abstract}
The Private Natural Heritage Reserve Veracel Station is located in the tourist city of Porto Seguro in Southern Bahia, Brazil. There is a Public Management Plan in this Conservation Unit that provides parameters for the visitation. Environmental education is the Program's main goal, and it consists of interpretive trails and local training courses without profit aim. Visitors are characterized by students, teachers of public and private schools, as well as professionals and researchers from national and international origins. Thus, the aim of this paper is to analyze the communication performed in visitation to the RPNN Veracel through observations of the Rainforest Trail, comparing techniques used in Environmental Education and Interpretation of the Environmental Heritage. For that we used the descriptive method to analyze the supply of the reserve, field research with photographic records and semi-structured observation, collected in the years 2011, 2012 and 2013, comparing with the theoretical framework on the Interpretation of the Natural Heritage and Environmental Education. This extensive Conservacion Unit preserves patches of primary Atlantic Forest, which host the harpy eagle species. The actions taken are relevant, but still little explored in regard to his immense potential of what education can offer.
\end{abstract}

KEYWORDS Veracel; Atlantic Forest; Tourism; Visitation; Cellulose. 


\section{Introdução}

As Reservas Particulares do Patrimônio Natural - RPPNs são Unidades de Conservação - UC de uso sustentável. Seu objetivo é, "a conservação da diversidade biológica tendo como base o plano de manejo, visando orientar a pesquisa científica e a visitação com objetivos turísticos, recreativos e educacionais" (BRASIL, 2002, p.26). A partir desta regulamentação no Brasil, houve um crescimento destas áreas, discussão sobre o seu uso, sua gestão, de forma a compreender os desafios enfrentados entre comunidades, visitantes, fauna e flora e gestores para a sua mais adequada manutenção.

$\mathrm{Na}$ Bahia, atualmente contamos com 91 RPPNs (BRASIL, 2011) criadas, em sua maioria, como medida mitigadora solicitada pelo órgão ambiental do estado, com a instalação de grandes empreendimentos turísticos e indústria. No extremo sul da Bahia, por exemplo, A RPPN Estação Veracel foi criada em 1998 já com plano de manejo, ocupando uma área de 6.069 hectares, sendo a maior reserva particular de Mata Atlântica da Bahia, como contrapartida ambiental após a instalação da empresa de celulose Veracel S.A. (VERACEL, 2007).

A RPPN EVC é uma das zonas núcleo da RESERVA DA BIOSFERA DA MATA ATLANTICA (UNESCO, 2000) localizada a $15 \mathrm{~km}$ do centro de Porto Seguro, às margens da BR 367, ligando os municípios de Eunápolis e Porto Seguro. A paisagem desta área foi transformada com a intensa extração de madeira de lei, criação de gado e atualmente com o plantio da celulose, mas ainda abriga espécies ameaçadas de extinção como o macaco-preto (Cebus robustus); o papagaio-chauá (Amazona rhodochorytha), o beija-flor balança-rabocanela (Glaucis dohrnii), e o Gavião Real (Harpia harpyja), que podem ser encontrados na reserva.

Esta RPPN, esta alicerçada pelo plano de manejo reestruturado em 2006 por uma equipe técnica e com o objetivo principal de minimizar os conflitos entres as comunidades locais e promover a educação ambiental para as mesmas, a partir de diversos programas executados no interior da reserva e em campo (IBAMA, 2004).

Sua localização privilegiada permite atuar em diversos municípios da região, onde a indústria trouxe muitos empregos, absorvendo mão de obra local, mas com pequeno resultado no que se refere à sustentabilidade ambiental.

O município de Porto Seguro é composto pelos distritos de Arraial D’Ajuda, Vale Verde, Vera Cruz, Trancoso e Caraíva, tendo como uma das principais atividades socioeconômicas o turismo. De acordo com o governo estadual e federal (PRODETUR NE II, 2002) o município está inserido em uma área prioritária para o desenvolvimento do turismo, denominada Costa do Descobrimento. O turismo neste pólo, por razão de sua importância ambiental e cultural, deve ser planejado para servir como fonte e distribuição de renda, instrumento de melhorias sociais para população local e incentivador da conservação dos patrimônios naturais e culturais (PRODETUR NE II 2002, 2003). 
Apesar da RPPN não estar aberta essencialmente para a visitação turística, esta funciona como uma área de atuação permanente da sua equipe para a educação ambiental das comunidades de forma que irá beneficiar as ações de preservação do meio ambiente para si e para o turista que visita a Costa.

\section{Metodologia}

Diante deste panorama, o objetivo principal deste artigo é analisar a visitação na RPPN Estação Veracel e especificamente, relacionar as atividades de Educação Ambiental com a Interpretação do Patrimônio e suas possíveis efetividades no contexto socioambiental da área.

A visitação esta baseada em informar ao visitante sobre a importância de conservação da natureza e principalmente a Mata Atlântica com o intuito de preservar o patrimônio natural tentando minimizar as áreas de conflito, localizadas nos arredores da reserva, estando pautada por cinco subprogramas ${ }^{1}$ do Programa de Uso Público. Quanto ao objetivo, a pesquisa se denomina descritiva, porque se deseja fazer uma análise das técnicas de comunicação utilizadas nas trilhas. Quanto à natureza, denomina-se básica, pois visa gerar novos conhecimentos para ciência despertando o interesse de caráter humano sem aplicação prática prevista (SILVA; MENEZES, 2005).

Nos procedimentos técnicos fez-se o levantamento de dados (SILVA; MENEZES, 2005, p.21), recorrendo-se a dados secundários, utilizando como base o Plano de Manejo da área. A pesquisa de campo foi realizada nos anos de 2011, 2012 e 2013 em acompanhamento de grupos escolares e universitários da região, onde se fez uma análise descritiva e registro fotográfico dos principais locais, verificando sua sinalização, a capacitação de seus funcionários bem como a segurança proposta na visitação, confrontando com as técnicas de Interpretação do Patrimônio e Educação Ambiental de forma a montar um quadro comparativo entre as técnicas utilizadas. Das cinco trilhas ${ }^{2}$ existentes analisou-se a mais utilizada pelos visitantes, a Floresta Tropical, sendo a maior em extensão e com maior número de atrativos.

Após a conclusão de todas as etapas citadas cruzou-se os dados, a fim de atingir os objetivos propostos.

\section{Educação Ambiental}

A educação, de maneira ampla, significa um processo contínuo de ações conjuntas e nunca de fatores isolados, que não deve limitar-se aos bancos escolares de um sistema formal (MORIM, 2000, apud HINTZE, 2008). Assim, considera-se que a educação ambiental é uma das várias formas de educação não-formal que pode oportunizar aos indivíduos uma consciência maior sobre sua função enquanto cidadão, de conservação de seu habitat. 
Todavia, tornar uma pessoa sensível ao meio ambiente não é algo que se estimule de forma fácil, é um processo lento em que o indivíduo deve compreender que os elementos que formam o meio ambiente fazem contribuem para a sua permanência de vida neste planeta. A partir desta compreensão e sensibilização, o homem pode transformar-se e se conscientizar da sua ação social e da sua capacidade de mudança sem apenas preocupar-se com o consumo de suas conveniências (SANDIVILLEJR; SUGUIMONTO, 2010).

Mais que produzir painéis solares mais baratos, reciclar e dotar os carros de células de combustível em vez de petróleo, precisa-se de um processo mais completo, que promova o desenvolvimento de uma compreensão mais realista do mundo. É preciso que se assuma o papel de oferecer mais formação e informação em uma caminhada evolucionária, e é através da Educação Ambiental que se pode alcançar este objetivo, procurando ser mais ágil e se adaptar aos novos desafios (DIAS, 2004).

\begin{abstract}
Entendem-se por educação ambiental os processos por meio dos quais o indivíduo e a coletividade constroem valores sociais, conhecimentos, habilidades, atitudes e competências voltadas para a conservação do meio ambiente, bem de uso comum do povo, essencial à sadia qualidade de vida e sua sustentabilidade (POLITICA NACIONAL DE EDUCAÇÃO AMBIENTAL, LEI № 9.795, Art. 1으, 1999).
\end{abstract}

Observa-se que o contato com a natureza é um bom estímulo à sensibilização sobre o meio ambiente e à sua conservação. Porém, há um espaço a preencher entre essa sensibilização e a Educação Ambiental. Neiman (2007, p.18) afirma que, se o contato com a natureza for oportunizado de forma adequada, estimulando todos os sentidos (sentir o cheiro da mata, olhar os animais, ouvir os barulhos), há uma melhora de sentimentos positivos em relação ao que deve ser conservado, afinal "não é apenas através do sentimento ético de obrigação que se pode trabalhar o gosto pela natureza e pela conservação".

Machado et al. (2013) cita um exemplo de atividades de educação ambiental em atrativos naturais realizadas em cinco fases e caracterizadas por diversos recursos pedagógicos, nos quais se busca concretizar objetivos específicos para cada uma. A primeira fase é a da observação, que consiste em fazer exercícios de percepção sensorial onde os indivíduos são estimulados a compreender o meio ambiente através dos cinco sentidos, vendo, ouvindo, sentindo o cheiro e as texturas que se apresentam no local. A fase do registro onde os indivíduos realizam descrição verbal ou escrita e fotografam, visa fixar o conhecimento recebido e melhorar a memória e o pensamento lógico. $\mathrm{Na}$ fase da exploração, os indivíduos são estimulados a analisar os problemas encontrados, desenvolver hipóteses, debater e preparar soluções. Na fase da apropriação, deve-se buscar atividades de recreação, visando o envolvimento das pessoas. 


\section{Interpretação do Patrimônio Ambiental}

Patrimônio é uma categoria de um pensamento nômade, que flutua ao longo do tempo e do espaço nas estruturas familiares, sociais, econômicas e jurídicas, e assume múltiplas qualificações: o genético, o natural e o cultural (CHOAY, 2001). Uma invocação mágica do passado, exercido no presente e planejado para que a futura geração o reconheça e continue a valorizá-lo como parte de uma ideia de bem comum.

Neste contexto, o patrimônio natural, pode ser considerado como formações físicas, biológicas e geológicas excepcionais, com grande valor científico, de conservação e estético, servindo ainda como abrigo para diversas espécies de fauna e de flora (UNESCO, 1972).

O ambiente natural começa a ser inserido em políticas de conservação no mundo, a partir da década de 1970, sendo atestado por cientistas, em contraponto com as grandes explorações e desastres ambientais causados pós-revoluções industriais. No Brasil, essa discussão chega somente na década de 1990, levando a criação de leis e decretos de proteção, seguindo o modelo de preservação ambiental que visava limitar as áreas, envolvendo educação ambiental, divulgadas principalmente pelos EUA nos parques de Yellowstone e Yosemite, onde foram elaboradas trilhas, espaços de contemplação, placas sinalizadoras e informativas, que despertassem ao visitante o interesse de conservação e mudança de atitude.

Desta forma, foi elaborado um conjunto de ações comunicacionais como base teórica para a interpretação ambiental proposta por Fremann Tilden na década de 1950, desenvolvidas e aplicadas a partir da visitação nos referidos parques. Assim, Tilden (1967 apud Murta, 2002, p.14) define a interpretação como:

...uma atividade educacional que objetiva revelar significados e relações através da utilização de objetivos originais, de experiência de primeira mão, bem como de mídia ilustrativa ao invés de simplesmente comunicar informações factuais.

Todavia, a base teórica parte da observação do comunicador, envolvendo o receptor, não apenas para receber a informação, mas para sensibilizar a ponto de obter mudança de postura e até mesmo atitude após esta experiência. É, sem dúvida, uma técnica que permite a transformação social a partir de uma vivência com a natureza em momentos de lazer, tendo um planejamento norteado por cinco princípios básicos, em que a ação comunicacional deve: provocar; relacionar; revelar; usar a mídia; apresentar o todo; e, utilizar uma linguagem acessível e diferentes abordagens para todas as idades.

Entende-se, assim, que é uma metodologia capaz de desnudar a memória coletiva, ressaltando as sutilezas de suas nuances, utilizando em sua estrutura técnicas de comunicação, envolvendo a percepção visual, a psicologia e a museologia de forma que o receptor/visitante seja estimulado 
a utilizar os seus cinco sentidos para a compreensão do patrimônio que esta sendo apresentado. Assim, os atrativos devem seguir um plano de interpretação no qual tenha uma história, um objetivo, seja dirigido a um determinado público e, principalmente, tendo claro qual a mudança que se deseja obter após o envolvimento de sensações e a aplicação comunicacional.

Mais tarde esta técnica é aperfeiçoada por Beck e Cable (1998), chegando a 15 princípios para a Interpretação, a saber: criar interesse; revelar; ter um enredo; provocar novas ações; apresentar o todo; ter diferentes abordagens para diferentes idades; trazer o passado à vida; utilizar novas tecnologias; dizer somente o suficiente; conhecer teorias de comunicação; utilizar escrita interpretada; realizar parcerias; encorajar a conservação; e, promover experiências únicas e paixão.

Com esses critérios pode-se verificar que a Interpretação do Patrimônio Ambiental vai além da proposta na educação ambiental, porque define objetivos para a comunicação que é trabalhada nos cinco sentidos de percepção do ser humano, atingindo a mudança de atitude esperada.

\section{A visitação}

Saindo de Porto Seguro, pela Rodovia BR-367, a RPPN EVC está no $\mathrm{km} \mathrm{37,} \mathrm{levando} \mathrm{em} \mathrm{média} 25$ minutos de viagem. Ao chegar no Km37, há uma placa de cimento indicando a RPPN, tendo a necessidade de percorrer ainda $1,5 \mathrm{Km}$ de estrada de barro até a recepção central que atende ao Centro de Visitantes e o Centro de Pesquisa.

Durante todo o percurso da estrada de barro pode-se encontrar placas indicando o limite de velocidade, $40 \mathrm{~km} / \mathrm{h}$, em português e inglês (Figura 1) e diversas placas educativas, alertando o visitante ao entrar na referida área (Figura 2).

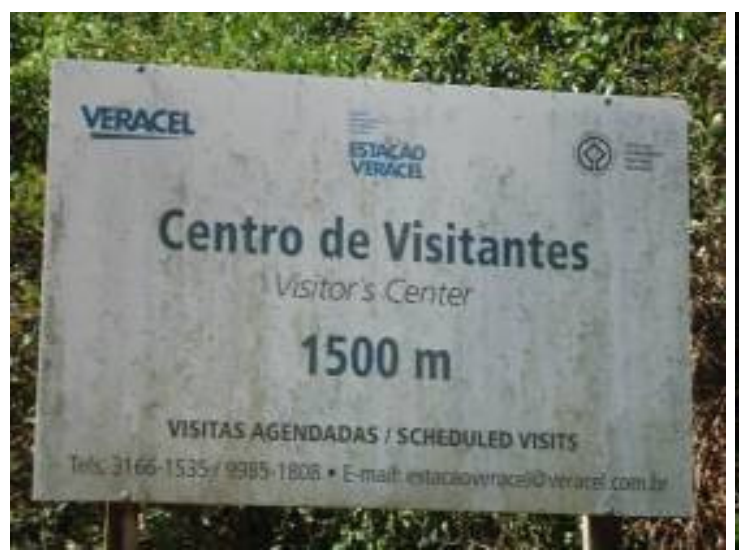

Figura 1: Placa indicativa com a distância a ser percorrida até a recepção da RPPN.

Fonte: Carvalho (2011)

Figure 1: Sign indicating the distance to be traveled to the RPPN reception.

Source: Carvalho (2011)

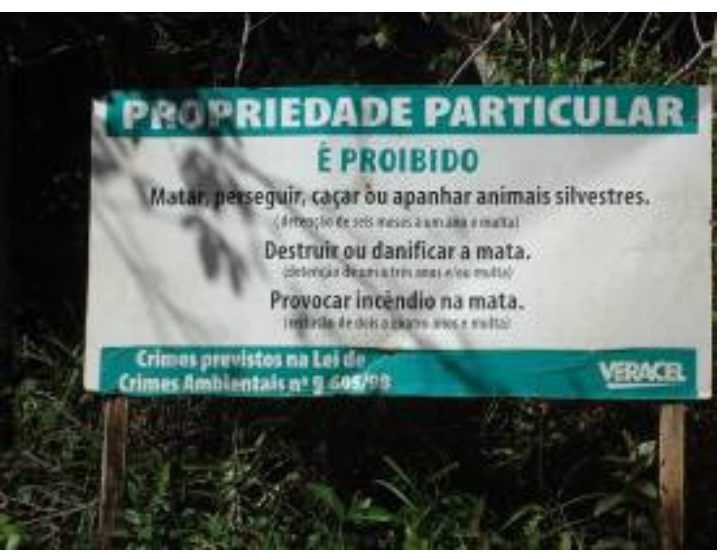

Figura 2: Placa informativa/ Fonte: Vieira (2014).

Figure 1: Information sign. Sourcee: Vieira (2014). 
$\mathrm{Na}$ recepção central pode-se encontrar telefone, walk talk, computador com sistema de segurança e extintor de incêndio, onde o funcionário comunica a chegada do grupo e encaminha para Centro de Visitantes ou para o Centro de Pesquisa.

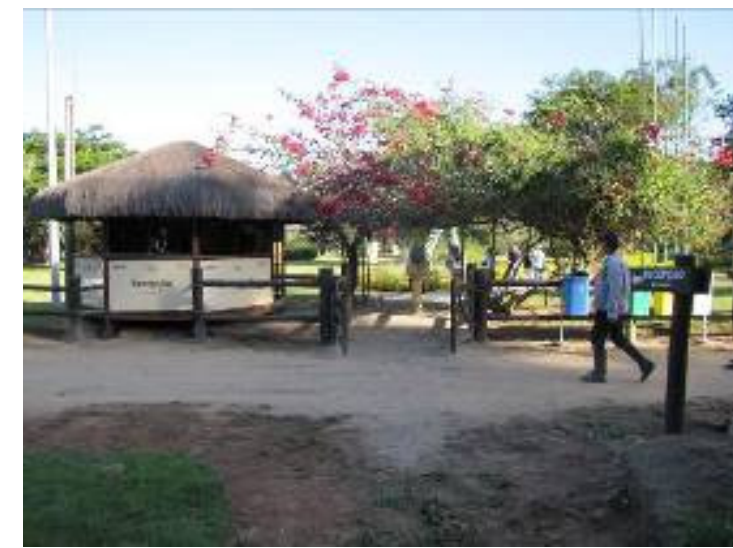

Figura 3: Recepção da RPPN. Fonte: Carvalho (2012). Figure 3: Reception.

Source: Carvalho (2012).

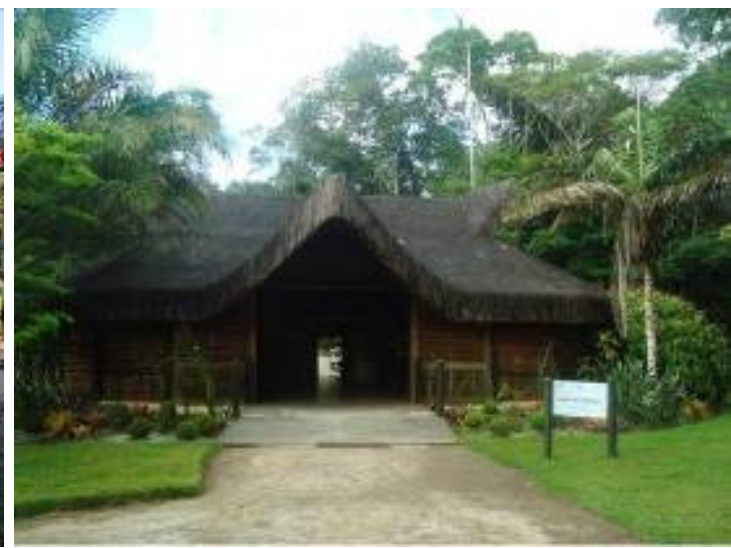

Figura 4: Centro de Visitantes Fonte: Vieira (2014). Figure 4: Vistors Center Source: Vieira (2014).

Antes do início das trilhas os grupos são direcionados ao Centro de Visitantes (Figura 4) que oferece uma estrutura com sala de reunião, sala de pesquisa e banheiros). Ali os monitores recepcionam o grupo e apresentam toda a estrutura da RPNN através de slides, música e dinâmicas com temas de conservação, gestão de resíduos sólidos, Mata Atlântica, fauna, bem como as atividades da indústria de celulose na região.

É importante sinalizar que foram avistados animais próximos ao Centro de Visitantes como beija-flor balança-rabo canela (Glaucis dorhnii), macaco preto (cebus robustus), jiboia (boa constrictor), cobra coral (micrurus corallinus) e sapo cururu (bufo marinus). O gavião real (harpia harpyja) é encontrado num viveiro próximo ao centro de visitantes, mas não é disponível à visitação, pois estes animais se encontram em reabilitação, sendo necessário minimizar o contato com o homem.

Da recepção até o Centro de Visitantes é possível perceber elementos comunicacionais sobre o contexto do local, conforme a Figura 5. A arquitetura utiliza elementos típicos da região combinados com o eucalipto em substituição à madeira de lei, antes muito utilizada nos domicílios e móveis locais (Figura 6).

O acesso para cadeirantes é disponível apenas na estrutura de Centro de Pesquisa. As trilhas ainda não são adaptadas para nenhum tipo de deficiência, mas estas estão em fase de preparação, conforme informação técnica.

Trabalham na Reserva 16 pessoas devidamente capacitadas e treinadas dividindo-se entre gestores, monitores, cozinheiras, guardasparques e serviços gerais. Os guias são de empresas terceirizadas, tendo noções de primeiros socorros e são monitorados pela equipe de segurança 
da EVC. Todos são uniformizados e utilizam equipamentos de segurança de acordo com cada atividade praticada individualmente ou em grupo.

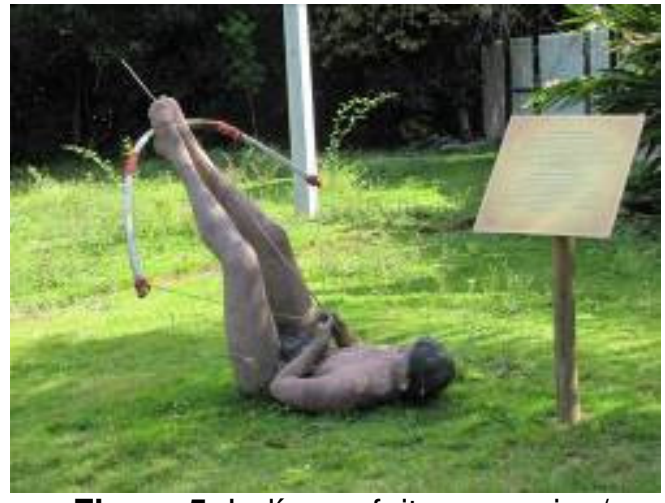

Figura 5: Indígena feito em resina/ Fonte: Carvalho (2012).

Figure 5: Indigenous made of resin. Source: Carvalho (2012).

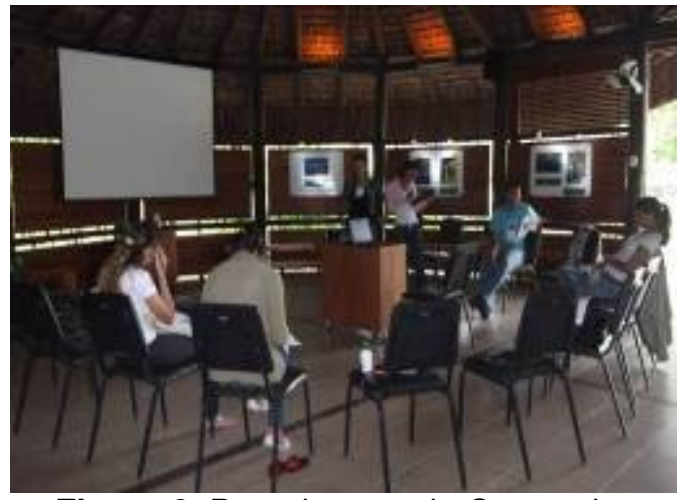

Figura 6: Parte interna do Centro de Visitante

Fonte: Carvalho (2013).

Figure 6: Inside the Visitor Center. Source: Carvalho (2013).

Conforme já informado, a RPPN tem dois objetivos: o de educação ambiental e da preservação da fauna e flora nativa. Para tanto se delineou um público alvo voltado para a educação ambiental, formado por crianças, jovens e adultos das escolas da região, grupos de igrejas, colaboradores da fábrica e seus familiares, atingindo também a todos que desejam visitar o espaço, sejam eles turistas nacionais ou internacionais.

A visitação é gratuita, para qualquer público. Desta forma a RPPN é mantida pela Fábrica Veracel S.A.

A visitação ocorre de segunda a sexta, de 09:00 horas às 17:00 horas, com atendimento máximo diário de 90 pessoas. As atividades e informações são adaptadas de acordo com o grupo que visita e devem ser agendados com antecedências para esta preparação. A equipe atua fora da Reserva com calendário especifico nas escolas, divulgando a área e promovendo ações no Dia da Água, Dia do Meio Ambiente, Dia do Planeta Terra, de forma a auxiliar os Parâmetros Curriculares Nacionais - PCN's nas escolas da região.

Não possuem acordo com agências de viagens e nem operadoras de turismo, mas caso queiram, as agências podem agendar visitação para pequenos grupos, com a participação do condutor do local e sem interferências externas de outros guias. Nos dias chuvosos as visitas às trilhas são canceladas.

$\mathrm{Na}$ transição de 2013 e 2014 foi observado um crescimento da demanda de turistas independentes, sobretudo de estrangeiros. Este fato deve-se à Copa do Mundo (FIFA), onde algumas das cidades serviram como Centro de Treinamento de Seleções-CT, como Porto Seguro e Santa Cruz Cabrália, região do RPPN. 


\section{Descrição das trilhas disponíveis para visitação}

Uma trilha pode ser definida, como uma rota, um caminho que liga pontos de interesse, apresentando forma, tema e função, de maneira a conectar visitantes com o lugar, sensibilizando-os e provocando mudanças para a conservação do meio ambiente, criando uma atmosfera positiva e influenciando a distribuição da informação a outros visitantes (IF, 2008; ANDRADE, 2003).

Na RPPN EVC, cada trilha só pode ser percorrida com grupos de até 20 pessoas por vez, para garantir a segurança e a qualidade na visitação. Menores de 07 anos e cadeirantes não podem participar. Antes de cada saída, são dadas recomendações para o comportamento na trilha, que dura em torno de 40 minutos, e consistem em: não gritar, não correr, não sair da trilha, olhar para o chão e prestar atenção para as informações do guia. Todos os participantes devem utilizar equipamentos de segurança como perneiras, calças de pano grosso, tênis e repelente contra insetos. O monitor avisa também que haverá momentos de paradas para registros fotográficos, informações sobre fauna e flora encontradas no percurso.

Importante salientar que as trilhas não têm mapas ilustrativos e/ou placas de sinalização. Não são, portanto, autoguiadas e devem ser percorridas obrigatoriamente com acompanhamento de um guia da Reserva. Existem cinco trilhas disponíveis para visitação, conforme plano de manejo apresentada no Quadro 1.

Quadro 1: Descrição das trilhas da RPNN EVC.

Table 1 Description of trails of the RPPN EVC.

\begin{tabular}{|c|c|c|c|}
\hline Nome & Forma & Extensão & Descrição \\
\hline $\begin{array}{l}\text { Trilha } \\
\text { Floresta } \\
\text { Tropical }\end{array}$ & $\begin{array}{l}\text { Circular } \\
\text { e } \\
\text { em oito }\end{array}$ & $\begin{array}{l}1.404,4 \mathrm{~m}^{2} \text { de } \\
\text { extensão, seu } \\
\text { percurso total (ida e } \\
\text { volta) é de } 2.808,8 \\
\mathrm{~m}^{2} \text {. }\end{array}$ & $\begin{array}{l}3 \text { horas e meia de caminhada, baixo grau de } \\
\text { dificuldade, vegetação bastante variada e } \\
\text { secundária, e os principais atrativos são: floresta } \\
\text { exuberante, exemplares arbóreos de grande } \\
\text { porte, ponte suspensa, cabana indígena, } \\
\text { armadilhas indígenas de caça e observação de } \\
\text { avifauna. }\end{array}$ \\
\hline $\begin{array}{c}\text { Trilha } \\
\text { Plataforma }\end{array}$ & Circular & $\begin{array}{l}193,20 \mathrm{~m}^{2}, \text { seu } \\
\text { percurso total (ida e } \\
\text { volta) é de } 307,8 \mathrm{~m} \\
(193,2 \mathrm{~m} \text { de trilha }+ \\
114,6 \mathrm{~m} \text { de estrada) }\end{array}$ & $\begin{array}{l}\text { 1:30 hora de caminhada, o grau de dificuldade é } \\
\text { baixo, floresta secundária e os principais atrativos } \\
\text { são: exemplar arbóreo de grande porte de figueira } \\
\text { Mata-Pau, plataforma sob árvores. }\end{array}$ \\
\hline $\begin{array}{l}\text { Trilha } \\
\text { Orquídea }\end{array}$ & Circular & $\begin{array}{l}214,9 \mathrm{~m}^{2}, \text { seu } \\
\text { percurso total (ida e } \\
\text { volta) é de } 429,8 \mathrm{~m}^{2}\end{array}$ & $\begin{array}{l}\text { 1:30 hora de caminhada, grau de dificuldade é } \\
\text { baixo, a floresta também é secundária, e seus } \\
\text { principais atrativos são: poucos exemplares de } \\
\text { orquidácea, caminhada na floresta. }\end{array}$ \\
\hline $\begin{array}{l}\text { Trilha das } \\
\text { Bromélias }\end{array}$ & Circular & $\begin{array}{c}403,7 \mathrm{~m}, \text { seu } \\
\text { percurso total é } \\
1.225,1 \text { (410,7m } \\
\text { trecho ida e volta em } \\
\text { estrada) }\end{array}$ & $\begin{array}{l}40 \text { minutos de caminhada, o grau de dificuldade é } \\
\text { baixo, floresta secundária e seus principais } \\
\text { atrativos são: atrativos: floresta, gradiente } \\
\text { topográfico, exemplares arbóreos de grande } \\
\text { porte. }\end{array}$ \\
\hline $\begin{array}{c}\text { Trilha Pau- } \\
\text { Brasil }\end{array}$ & $\begin{array}{l}\text { Circular, } \\
\text { linear e } \\
\text { em oito, }\end{array}$ & $\begin{array}{l}1.809,6 \mathrm{~m}, \text { seu } \\
\text { percurso total (ida e } \\
\text { volta) é de } 3.241,0 \\
\mathrm{~m}^{2}\end{array}$ & $\begin{array}{l}2: 30 \text { horas de caminhada, o grau de dificuldade é } \\
\text { baixo a moderado, a floresta é secundária e os } \\
\text { principais atrativos são floresta exuberante, } \\
\text { exemplares arbóreos de grande porte, ponte (que } \\
\text { no momento está desativada para reparos). }\end{array}$ \\
\hline
\end{tabular}

Fonte: Adaptado do Plano de Manejo (2007).

Source: Adapted from Management Plan (2007). 
A Trilha Floresta Tropical, objeto desta pesquisa é considerada a mais visitada por apresentar maior biodiversidade. O tempo de percurso é menor e o grau de dificuldade, fácil. A única placa encontrada é de indicação que esta localizada logo na entrada da trilha (Figura 7).

Os aspectos da fauna só são explicitados quando algum animal é avistado. Porém, foram inseridos ao longo da trilha diversos animais presentes da Mata Atlântica feitos de resina como a anta (Figura 8) e a onça parda. Isso confere a visitação mais interesse por parte dos visitantes, que a primeira vista pensam que é um animal de verdade.

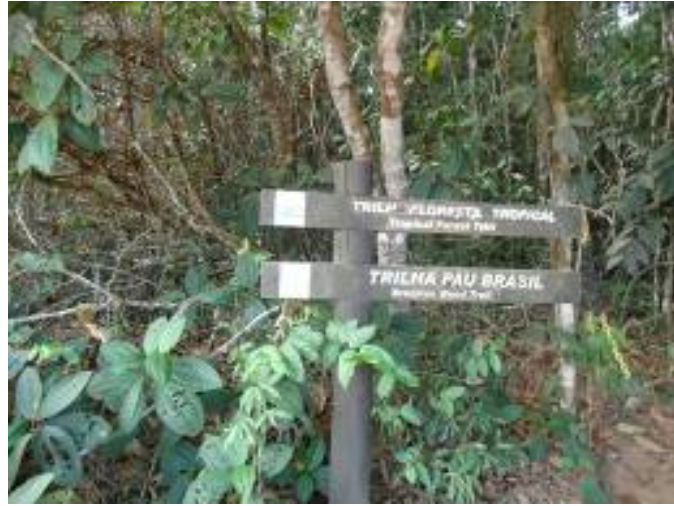

Figura 7: Placa Indicativa da Trilha Floresta Tropical. Fonte: Vieira (2014). Figure 7: Sign of Tropical Forest trail. Source: Vieira (2014).

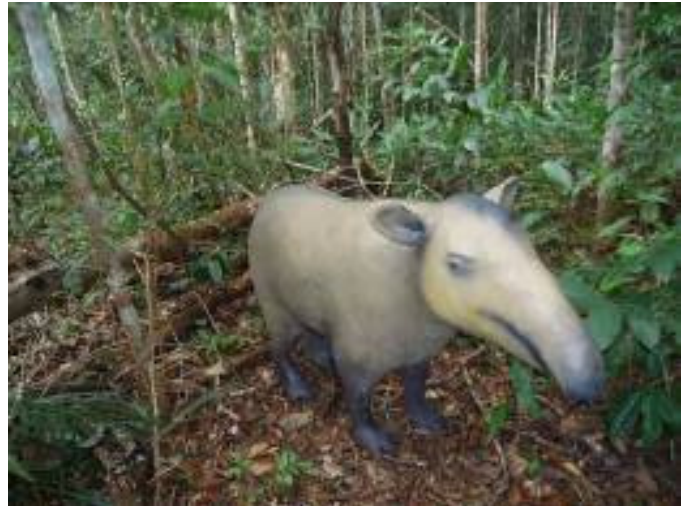

Figura 8: Anta feita de resina, disposta na trilha Floresta Tropical. Fonte: Vieira (2014).

Figure 8: Tapir made in resin. Source: Vieira (2014).

Já os aspectos sobre a flora são mais aprofundados, existindo momentos exclusivos para a apresentação de espécies como patioba (syagrus botryophora), vick (mentha arvensis) e amescla (trattinickia rhoifolia willd). São expostas, nesta ocasião, informações sobre o tamanho, uso popular, forma da folha, cheiro característico e textura das espécies. $O$ condutor informa também sobre a mata Ombrofila Densa com formação de bosque e sub-bosque (Figura 9), e suas respectivas alturas apontando as áreas específicas.

Há na trilha uma ponte suspensa (Figura 10), com a altura média de dois metros, onde o visitante precisa ultrapassar para dar continuidade à caminhada. Nela eles conseguem visualizar espécies de bromélias, que não são pisoteadas, além de várias espécies de plantas do sub-bosque.

No final da trilha o condutor confere o número de pessoas que participaram da trilha e os encaminha para o Centro de Visitantes. Neste momento, os condutores questionam os participantes sobre a percepção de toda visita de forma a trocarem informações e sensações durante 0 percurso. Encerrando a visita, o grupo é convidado a assinar um livro de registros sobre as impressões da visitação. 


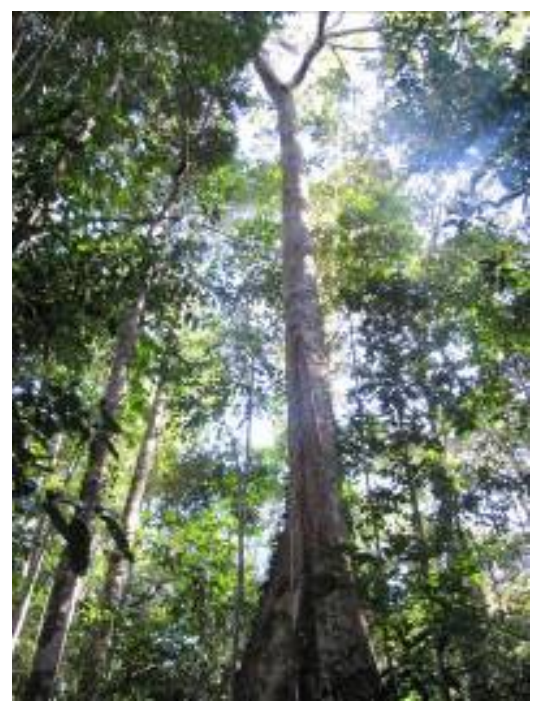

Figura 9: Mata Ombrofila densa. Fonte: Carvalho (2013).

Figure 9: Antlantic Forest. Source: Carvalho (2013).

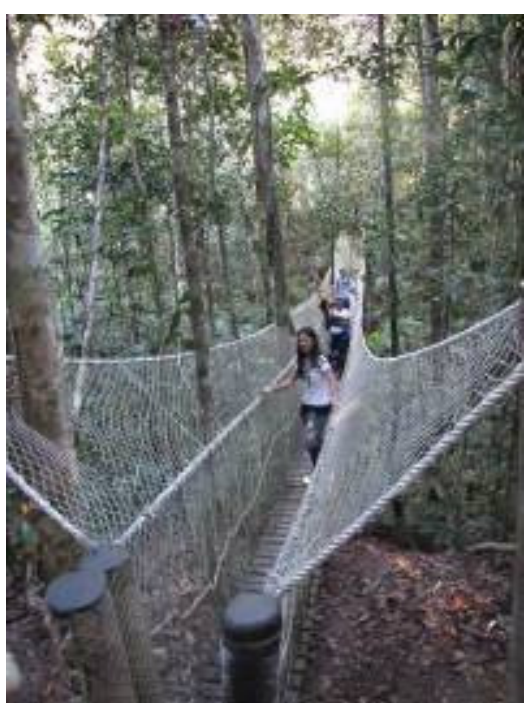

Figura 10: Ponte suspensa. Fonte: Vieira (2013).

Figure 10: Suspended bridg. Source: Vieira (2013).

\section{Análise Educação Ambiental x Interpretação Ambiental}

Para atender aos objetivos propostos nesta pesquisa (Quadro 2) estão as análises das ações desenvolvidas na educação ambiental e interpretação ambiental, destacando alguns aspectos de grande relevância para a concretização das propostas. Considera-se também um desafio envolver o homem da atualidade em questões ambientais onde a lógica é consumo (DIAS, 2004).

Compreende-se que ao se mencionar termos técnicos é necessário fixar a informação ao visitante, trazendo para sua realidade ou cotidiano os pontos levantados durante a fala, principalmente no que se refere ao tempo disponível para obter as informações de conservação do meio ambiente. Acredita-se, assim, que a partir das experiências vivenciadas durante a trilha Floresta Tropical, a educação ambiental esteja inserida no processo de visitação, que deve possibilitar a transformação ativa da realidade e das condições da qualidade de interação com o meio ambiente para o dia-a-dia, por meio da prática social reflexiva embasada pela teoria do conhecimento (LOUEIRO, 2006). Neste momento o visitante terá a possibilidade de ver, sentir, ouvir e pegar em determinadas texturas de forma a desenvolver uma sensibilização para a proteção do meio ambiente e mudança na forma de consumo. Mas, acredita-se que este seja um momento inicial e que o processo de aprendizado e sensibilização deva ter continuidade em outros espaços.

No que se refere à Interpretação Ambiental, sua metodologia é pouco utilizada na trilha, mas se melhor direcionada agregaria valor e eficiência na visitação, para a efetiva mudança de atitude. Foi observado que os elementos de fauna e flora, bem como os aspectos históricos da Mata Atlântica não são bem trabalhados de acordo com o seu enorme potencial. As comunidades do entorno são pouco referenciadas na trilha, de modo que o visitante não conhece as dificuldades e nem as peculiaridades destas. 
Quadro 2: Análise das ações de Educação Ambiental e Interpretação Ambiental.

Table 2: Analysis of the actions of the Environmental Education and Environmental Interpretation.

\begin{tabular}{|c|c|c|}
\hline Ação realizada & Educação Ambiental & Interpretação Ambiental \\
\hline \multicolumn{3}{|l|}{ Recursos } \\
\hline $\begin{array}{l}\text { Recursos } \\
\text { Humanos }\end{array}$ & $\begin{array}{l}\text { Observa-se que os grupos atendidos pela } \\
\text { equipe da RPNN Veracel buscam alcançar } \\
\text { objetivos pré-definidos antes da visitação, } \\
\text { sempre relacionados ao meio ambiental, a partir } \\
\text { daí a equipe adaptara objetivos da EA da RPPN } \\
\text { e objetivos do visitante. }\end{array}$ & $\begin{array}{l}\text { A equipe traz informações } \\
\text { factuais sobre o meio ambiente. } \\
\text { Porém não utiliza técnicas } \\
\text { específicas da l.P. para } \\
\text { estimular/provocar } \\
\text { interpretação do visitante. }\end{array}$ \\
\hline $\begin{array}{l}\text { Equipamentos } \\
\text { Disponíveis }\end{array}$ & $\begin{array}{l}\text { Desenvolve oficinas de reciclagem com garrafas } \\
\text { PET e tetra pak; } \\
\text { Áudio visual para vídeos sobre a fábrica e sobre a } \\
\text { RPPN; } \\
\text { Trilhas para visitação; } \\
\text { Exposições temporárias com animas feitos de } \\
\text { resina. } \\
\text { Ponte pênsil }\end{array}$ & $\begin{array}{l}\text { Em } 2012 \text { existia uma exposição } \\
\text { interativa com labels; } \\
\text { Ponte pênsil. }\end{array}$ \\
\hline Temas & $\begin{array}{l}\text { O tema principal é a preservação da Mata } \\
\text { Atlântica, realizando poucos vezes a ligação } \\
\text { com o cotidiano dos visitantes. }\end{array}$ & $\begin{array}{l}\text { Não definido conforme as } \\
\text { técnicas de Interpretação do } \\
\text { Patrimônio - IP. }\end{array}$ \\
\hline Mercado & Item não relevante para Educação Ambiental & $\begin{array}{l}\dot{E} \text { necessário destacar perfil do } \\
\text { visitante, formas comunicacionais } \\
\text { para que a partir deste aspecto os } \\
\text { temas de preservação e } \\
\text { conservação sejam alcançados, } \\
\text { obtendo também a } \\
\text { sustentabilidade econômica. } \\
\text { Entretanto, este não é o foco da } \\
\text { RPPN. }\end{array}$ \\
\hline $\begin{array}{l}\text { Meios e } \\
\text { Técnicas }\end{array}$ & & \\
\hline $\begin{array}{l}\text { Intepretação ao } \\
\text { vivo }\end{array}$ & \multicolumn{2}{|c|}{$\begin{array}{l}\text { A interpretação ao vivo é a utilização de técnicas teatrais para representar o tema. } \\
\text { Não sendo aplicado na RPPN. }\end{array}$} \\
\hline $\begin{array}{c}\text { Textos e } \\
\text { Publicações }\end{array}$ & \multicolumn{2}{|c|}{ Não são utilizados folders, mapas e nenhum elemento impressos. } \\
\hline $\begin{array}{l}\text { Placas, Painéis } \\
\text { e Letreiros }\end{array}$ & $\begin{array}{l}\text { A sinalização é bem realizada até a chegada ao } \\
\text { Centro de Visitantes. Contudo, as trilhas não } \\
\text { são sinalizadas, existindo apenas placas } \\
\text { indicativas e numeração de espécies de flora. }\end{array}$ & $\begin{array}{l}\text { Existem placas } \\
\text { informativas } \\
\text { interpretativas. }\end{array}$ \\
\hline $\begin{array}{l}\text { Modelos e } \\
\text { reconstruções }\end{array}$ & \multicolumn{2}{|c|}{$\begin{array}{l}\text { Durante as oficinas realizadas pela equipe da RPPN nas escolas das cidades do } \\
\text { entorno eles utilizam maquetes representando o Centro de Visitantes e animais da } \\
\text { Mata Atlântica. Contudo, estas não são apresentados na RPPN. }\end{array}$} \\
\hline $\begin{array}{l}\text { Reconstrução } \\
\text { do passado }\end{array}$ & \multicolumn{2}{|c|}{$\begin{array}{l}\text { Seja na trilha ou na apresentação no Centro de Visitantes, os condutores em } \\
\text { nenhum momento referenciam a comunidade do entorno nem seus antigos } \\
\text { habitantes. Apesar de ter elementos físicos para essa representação, conforme já } \\
\text { indicado, as comunidades são lembradas quando são feitas perguntas especificas. }\end{array}$} \\
\hline Design & \multicolumn{2}{|c|}{$\begin{array}{l}\text { Utilização de esculturas representando os animais e a comunidade do entorno ao } \\
\text { longo da RPPN. }\end{array}$} \\
\hline Promoção & $\begin{array}{l}\text { E realizada divulgação nas escolas dos } \\
\text { municípios do entorno através de palestras e } \\
\text { exposições. A RRPN participam também de } \\
\text { grandes eventos relacionados ao meio } \\
\text { ambiente. }\end{array}$ & 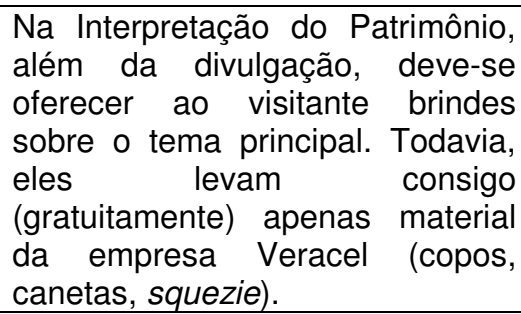 \\
\hline
\end{tabular}

Fonte: Adaptado de Murtha (2002).

Source: Adapted from Murtha (2002). 


\section{Conclusão}

O Processo de educação ambiental no Brasil segue as orientações da Política Nacional de Educação Ambiental (Lei 975/99) que vem agregar valor ao Sistema Nacional de Unidades de Conservação (SNUC, 2000), fazendo com que instituições de ensino formal ou não tenham corresponsabilidades para com as ações de preservação e conservação do meio ambiente no país.

Apesar de tardia e ainda pouco eficiente em sua aplicação nas UC brasileiras, à educação ambiental tem sido primordial para o fortalecimento e ampliação dessas áreas, onde comunidades, Estado e governo começam a dialogar sobre seus respectivos interesses e responsabilidades.

Sem dúvida a RPNN EVC tem um papel importante na educação ambiental da região, onde desenvolve um duplo papel, atender a comunidade em seu espaço e levar informação às escolas. Mas, é necessário compreender que o processo da educação ambiental é longo e contínuo e normalmente desenvolvido com técnicas de percepção e aprendizagem. Este processo pode ser bem desenvolvido no papel exercido pela RPPN nas escolas, contribuindo com o ensino local. Em contrapartida, na visitação, a Interpretação do Patrimônio Ambiental oferece técnicas efetivas para abordagem do visitante, pois utiliza a comunicação direcionada para a mudança de atitude, considerando o pouco tempo disponível, além de atuar no desenvolvimento cultural das comunidades locais.

Desta forma, é necessário compreender que o homem conserva aquilo que conhece, entende e reconhece a importância dos elementos que compõem o meio ambiente para a sua vida. Portanto informar apenas não basta, é necessário compreensão, sensibilização e direcionamento de ações para que a mudança de atitude seja efetivada, respeitando cada realidade, cada cultura de acordo com o tempo disponível para as atividades educacionais.

Os temas desenvolvidos na educação ambiental como consumo consciente, resíduos sólidos, sustentabilidade são destacados na visitação antes da trilha, mas há uma carência no desenvolvimento de atividades que relacionem o cotidiano do visitante com a Mata Atlântica, o principal objetivo desta UC.

A trilha é curta permitindo que diversos públicos possam realiza-la. $\mathrm{Na}$ entrada da mata é possível observar a queda de temperatura, promovida pela aproximação e copa das árvores, favorecendo bem estar e tranquilidade na caminhada. Os pontos de parada permitem a observação de fauna e flora, mas com pouca relação ao cotidiano das comunidades locais.

Aponta-se para a carência de sinalização interpretativa, capaz de sensibilizar o visitante e não apenas informa-lo ou ordenar o que deve ou não se fazer dentro do espaço visitado. Indica-se um maior envolvimento com as histórias locais, bem como informar sobre o uso popular da flora nativa. Como processo de aprendizagem e de indicação de responsabilidades ao visitante, sugere-se a implantação de viveiros de mudas com espécies nativas, de forma a contemplar as suas formas de manejo, fases de crescimento para que a comunidade e visitante possam conhecer a Mata Atlântica tão devastada nesta região. As mudas ainda podem ser presenteadas e/ou vendidas após a visitação 
Espera-se que esta pesquisa possa contribuir para maior aprofundamento da temática e desperte o interesse de aplicação em outras unidades de conservação no que tange as técnicas de interpretação ambiental e educação ambiental no Brasil.

\section{Referências bibliográficas}

ANDRADE, W.J. Implantação e manejo de trilhas. In: WWF. Manual de ecoturismo de base comunitária: ferramentas para um planejamento responsável. Brasília. WWF Brasil. p. 247-260. 2003.

BECK, L; CABLE,T. Interpretation for the 21st Century: Fifteen guiding principles for interpreting nature and culture. Sagamore Publishing, 1998. $335 \mathrm{p}$.

BRASIL. Decreto-Lei no 9.795, de 27 de abril de 1999. Diário Oficial, Brasília: DF; $1999 . \quad$ Disponível em: $<$ http://www.mec.gov.br/se/educacaoambiental/pdf/lei979599.pdf> Acesso em: 23 out. 2005.

BRASIL. Ministério do Meio Ambiente. Estruturas. Mapa Mata Atlântica, 2011.

Disponível

em:<http://www.mma.gov.br/estruturas/202/ arquivos/mapa mata atlantica verso 202.pdf>Acesso em 20 abr. 2014

BRASIL. Sistema Nacional de Unidade de Conservação - SNUC (Lei $n$. 9.985). Brasília: Ministério do Meio Ambiente e da Amazônia Legal, 2000.

CHOAY, F. Alegoria do patrimônio. São Paulo: Estação Liberdade e UNESP, 2001. $282 \mathrm{p}$.

DIAS, G.F. Educação Ambiental: princípios e práticas. 9.ed. São Paulo: Gaia, 2004. 116 p.

HINTZE, H.C. Ecoturismo na cultura de consumo: possibilidade de Educação Ambiental ou espetáculo? Dissertação de Mestrado: ESALQUSP, 2008. 137 p.

IF. Instituto Florestal. 2008. Manejo de trilhas: um manual para gestores. São Paulo: Instituto Florestal, 2008. 74 p.

LOUREIRO, C.F.B. Trajetória e fundamentos da educação ambiental. 2. Ed. São Paulo: Cortez, 2006. 150 p.

MACHADO, S.F.; MONTEIRO, J.C.L., ALVES, K.S. Educação Ambiental como promotora de consciência ambiental na rede pública de ensino de Ouro Preto (MG). Revista Brasileira de Ecoturismo, São Paulo, v.6, n.1, p. 233-254, jan/abr-2013.

MURTA, S.M.; GOODY, B. Interpretação do patrimônio para visitantes: um quadro conceitual. In: MURTA, S.M.; ALBANO, C. (orgs). Interpretar o patrimônio: um exercício do olhar. Belo Horizonte - MG: Ed. UFMG; Território Brasilis, 2002. p. 9 - 46. 
NEIMAN, Z. O cerrado como instrumento para Educação Ambiental em atividades de Ecoturismo. In: NEIMAN, Z. (org) Meio ambiente, Educação e Ecoturismo. Barueri, SP: Manole, 2002.

PRODETUR II. Programa de Desenvolvimento do Turismo no nordeste II. Banco do Nordeste. Disponível em: http://www.bnb.gov.br/content/aplicacao/prodetur/polos/gerados/prodetur pol os principal.asp. Acesso em: 20 abr 2014.

SANDEVILLE-JR, E.; SUGUIMOTO, F.T. Ecoturismo e (Des)Educação Ambiental. Revista Brasileira de Ecoturismo, São Paulo, v.3, n.1, p. 47-60, 2010.

SILVA, E.L.; MENEZES, E.M. Metodologia da pesquisa e elaboração da dissertação. 4. ㄹ ed. Florianópolis; UFSC, 2005.

UNESCO. Organização das nações unidas para a educação, a ciência e a cultura. Convenção para a proteção do patrimônio mundial, cultural e natural. 1972. Disponível em: http://whc.unesco.org/archive/convention-pt.pdf Acesso em: 20 abr 2014.

VERACEL, Celulose S/A. Plano de Manejo. Disponível em: <www.veracel.com.br> Acesso em: 01 abr. 2013.

\section{Notas:}

1 Subprogramas: de Interpretação ambiental; Educação Ambiental; Capacitação; Monitoramento do Uso Publico e Manutenção de Trilhas. Disponíveis no Plano de Manejo: www.veracel.com.br

${ }^{2}$ Pau-Brasil, Floresta Tropical, Plataforma, Bromélias e Orquídea

Renata Coppieters Oliveira de Carvalho: Universidade do Estado da Bahia, Eunápolis, BA, Brasil.

E-mail: renatacopi@hotmail.com

Link para o currículo Lattes: http://lattes.cnpq.br/9880513754068888

Salete Vieira: Universidade do Estado da Bahia, Eunápolis, BA, Brasil.

E-mail: saletur@hotmail.com

Link para o currículo Lattes: http://lattes.cnpq.br/6303208147561941

Data de submissão: 29 de abril de 2014

Data de recebimento de correções: 08 de outubro de 2014

Data do aceite: 08 de outubro de 2014

Avaliado anonimamente 